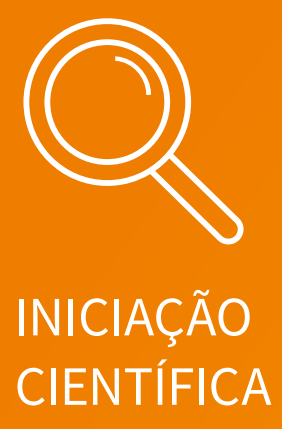

\title{
A versatilidade da roupa feminina e a luta diária da mulher durante a segunda guerra mundial
}

\author{
A versatility of women's clothing and a daily \\ struggle of women during a second world war
}

Laiana Pereira da Silveira

http://lattes.cnpq.br/4493023707282382

Frantieska Huszar Schneid [orientadora]

http://lattes.cnpq.br/2346887754842567

\section{Resumo}

Este artigo aborda a questão da vestimenta feminina durante o período da Segunda Guerra Mundial e a versatilidades das peças usadas pelas mulheres que precisaram sair de casa para trabalhar, resgata a importância dessas mulheres que mostraram ao mundo a força da sua independência, mulheres que passaram a serem vistas de frágeis a verdadeiras guerreiras, que precisaram sair do conforto de suas casas para trabalhar e sustentar suas famílias. Também é discutida a influência da vestimenta masculina no guarda-roupa feminino, devido aos uniformes usados pelos soldados e a questão da regulamentação para a criação das peças de vestuário devido à escassez de matéria-prima.

\section{Palavras-chave}

Moda. Segunda Guerra Mundial.

Mulher. Escassez. Indumentária.

\section{Abstract}

This article addresses the issue of women's clothing during the period of the Second World War and the versatility of the parts used by women who had to leave home to work, rescues the importance of those women who showed the world the strength of its independence, women now they are seen fragile the true warriors, who had to leave the comfort of their homes to work and support their families. It is also discussed the influence of male dress in women's wardrobe because of the uniforms worn by soldiers and the issue of regulation for the creation of the garments due to shortage of raw material.

\section{Keywords}

Fashion. Second World War.

Woman. Scarcity. Clothing.

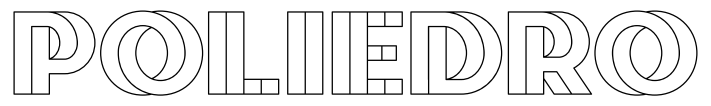




\section{Introdução}

O presente artigo possui como temática principal, a indumentária usada pelas mulheres durante o período histórico da Segunda Guerra Mundial, e a partir desta proposta, procurou-se encontrar uma delimitação de tema com informações e detalhes suficientes que pudessem enriquecer ainda mais um projeto ligado à moda, escolheu-se abordar a versatilidade da roupa feminina durante a guerra, sabendo que nesse período a mulher que era considerada frágil, viu-se obrigada a mudar sua rotina, assumir uma postura forte, sair do lar para trabalhar em fábricas, transformou-se de dona de casa a operária.

O fim dos anos de 1930 foi marcado pelo início da Segunda da Guerra Mundial, conflito que durou entre os anos de 1939 a 1945, envolvendo inúmeras nações do mundo e que mudou rumos da história, deixando marcas até a atualidade. A moda começou a ganhar influência da vestimenta masculina pelos uniformes usados pelos soldados, o guarda-roupa feminino tornou-se mais sóbrio, rígido e prático.

Tema rico em informações históricas e culturais traz a importância da mulher no período abordado, visto que a mesma mostrou ao mundo a força da sua independência, mulher essa que foi fundamental para que as fábricas não parassem de funcionar. Sabemos que a Segunda Guerra mudou o formato das roupas, devido ao racionamento de tecidos e regulamentação do seu uso, segundo os autores Fiell e Dirix:

\footnotetext{
$<<$ As restrições, o racionamento e as medidas de austeridade tiveram forte impacto na composição da moda. Em termos práticos, isso se traduzia em uma quantidade muito mais limitada de tecido; a seda tornou-se indisponível, pois foi direcionada aos esforços de guerra, e a lã existia em quantidades bastante reduzidas. Corantes tinham uso restrito, e dizia-se que as roupas tornaram-se monótonas, embora isso não fosse um fato universal. Tons de cinza, azul, verde e marrom dominavam a paleta. (FIELL e DIRIX, 2014, p. 40).
}

Portanto, a moda precisou se adaptar as circunstâncias precárias, as peças precisavam ser práticas e confortáveis para o seu uso. 
$O$ atual artigo tem como um dos objetivos mostrar como um fenômeno político, a Segunda Guerra Mundial, refletiu-se na vestimenta feminina da mulher que foi obrigada a sair do lar, até então conhecido por ela como zona de conforto.

\section{A versatilidade da roupa feminina}

A década de 1940, inicia devastada pela guerra. A silhueta de estilo militar imposta no final dos anos 1930, durou até o final do conflito. Para os autores Fiell e Dirix,

\footnotetext{
$<$ A década de 1940 pode ser divida em duas metades iguais: a primeira testemunhou a Segunda Guerra Mundial, o conflito internacional mais brutal da história, com a maior perda de vidas de todas as guerras até então, e a segunda foi o momento de resgate da paz. Embora pouco mais da metade da década tenha sido marcada pelo conflito, sua influência foi sentida em todo o período, seja nos fatos do dia a dia ou em suas consequências (FIELL e DIRIX, 2014, p. 6).
}

Logo, a Segunda Guerra mostrou-se como uma catástrofe mundial, que mudou o rumo da história de todas as nações envolvidas, na grande maioria com danos e perdas irreparáveis, as vidas que ali terminaram e as marcas nos sobreviventes jamais serão esquecidas.

Já introduzindo a questão têxtil desse período, a autora Pollini diz que, "em 1941, entrou em voga o "Cartão de Vestuário", que determinava a quantidade de roupas que os franceses podiam consumir" (POLLINI, 2007, p. 59), o governo extremamente controlador impôs as mulheres o uso do "Cartão do Vestuário", que era por meio de cupons, onde cada vez que era comprado tecido, ia sendo abatida a quantidade dos mesmos, cada uma tinha direito a um valor exato para adquirir anualmente. Esta solução criada e imposta pelo governo foi mal recebida pela população, porém fazia-se necessária diante das circunstâncias do período, e quanto mais se estendia a guerra, mais rigorosa era a fiscalização dos consumidores desses produtos. Pollini também conta que o governo: 
Determinava a quantidade de roupas que os franceses podiam consumir, por meio de cupons. Depois, seguiu-se o regulamento do desenho das roupas, com o objetivo de economia da metragem de tecido. No vestuário feminino, o número de pregas e botões foi limitado; as saias iam até a altura do joelho e deveriam ser justas, nada de saias rodadas (POLLINI, 2007, p. 59).

Os consumidores estavam passando por inúmeras dificuldades, e os profissionais que trabalhavam com moda - costureiras, modistas, alfaiates -, estavam sofrendo com este período de escassez no mercado de vestuário. 0 racionamento de tecido limitava as criações e o setor de moda precisava criar alternativas para não perder seus clientes e ao mesmo tempo estar dentro das normas estipuladas pelo governo no período de guerra.

Tratando-se também da questão de necessidade de materiais e diminuição de custo, o autor Blackman destaca que "a lã custava menos cupons do que a roupa pronta; portanto, tricotar era econômico e útil” (BLACKMAN, 2011, p. 152), as mulheres viam-se obrigadas a comprar lã e confeccionar seus próprios pulôveres como forma de economia, sendo também, de certa forma, uma forma de diferenciação através da exclusividade da peça. A questão do sistema de racionamento das roupas, imposto pelo governo é trazida pelo autor Blackman, que afirma:

\footnotetext{
$<<$ O sistema de racionamento de roupas foi introduzido na Grã-Bretanha em 1941 como esforço para garantir a distribuição justa das mercadorias disponíveis. No início, eram distribuídos 66 cupons por ano por pessoa, mas esse número diminuiu à medida que a guerra continuava (BLACKMAN, 2011, p. 168).
}

Foi desta maneira que o governo da Grã-Bretanha encontrou uma forma de distribuição igualitária dos produtos que haviam disponíveis para a população. Devido a escassez, a roupa ficou marcada pela função utilitária e sem muitos detalhes, podendo-se assim observar a uniformização da mesma, com ares masculinizados, com o uso de ombreiras acentuadas e o corte reto. Braga, afirma que: 
$<$ De 1939 a 1945, a palavra de ordem foi recessão. Obviamente que a moda não ficou fora desse contexto. As roupas femininas, de fato, masculinizaram-se e a grande moda foi o uso de duas peças, para qualquer momento, fosse do dia ou da noite. Saias bem mais justas e casacos compunham a toalete feminina em tecidos simples e que normalmente eram racionados. Havia inclusive regras para gastos de tecidos e também para a limitação de metragem de compra [...] Isso tudo provocou uma certa monotonia na moda, que foi resolvida com detalhes específicos como debrum colorido, bolsos e golas também de outra cor etc., como forma de aproveitamento de sobras de tecido (BRAGA, 2004, p. 69).

Nesse período, junto com a recessão, surgiu o reaproveitamento de tecidos e de peças que não eram mais utilizadas, ou seja, a população viu-se obrigada a enxergar métodos de tornar útil todo e qualquer artigo de vestuário que havia sido tirado de uso. Apesar da situação precária, conseguiu-se tirar proveito do momento, pois devido à escassez de tecidos, houve mais pesquisas sobre novas tecnologias na área têxtil, fazendo com que as mulheres adotassem materiais alternativos para o uso naquela época, reformando suas roupas com tecidos do tipo viscose e o raiom, que substituíram a seda - usada pelos soldados no campo de batalha - e os sintéticos produzidos a partir do petróleo. De acordo com Stevenson:

Com a escassez da guerra, os comprimentos das saias subiram, e os shorts e saias-calças eram comuns para o ciclismo, cada vez mais praticado dados o confisco dos carros e a escassez de combustível. Havia constante preocupação com a falta de meias de nylon e, quando não ganhavam nenhuma de soldados, as moças tinham de usar meias soquete ou pintar as pernas com uma mistura de sal e corante caramelo (STEVENSON, 2012, p. 126).

Nesse período, com o homem recrutado para os campos de guerra, longe do lar por tempo indeterminado, a mulher enxerga-se obrigada a ir trabalhar nas fábricas, na produção de armamentos, de munição, de roupas e também de alimentos. 


\section{A moda na década de 40}

A moda no final dos anos 30 e na primeira metade da década de 40 chega sem cores e rígida, limitada pelo governo, tornando-a quase sem graça, porém, a indústria da moda adquiriu importância vital para manter a economia relativamente bem. Taylor assegura que:

\footnotetext{
$<<$ Em contraste com as linhas sinuosas e sensuais da década anterior, a de 1940 trouxe formas quadradas severas, ombros largos, saias mais curtas, chapéus excêntricos e sapatos pesados. [...] As peças precisavam ser práticas e confortáveis, já que as mulheres assumiram o lugar dos homens no mercado de trabalho [...] Calças funcionais, saias pregueadas, vestidos clássicos acinturados com gola de camisa e botões, ou levemente estruturados, davam liberdade do movimento (TAYLOR, 2014, p. 58).
}

Através do cenário da guerra e do novo estilo de vida da população perante o caos, adaptadas aos novos tempos, a moda e a ação de vestir-se passaram a se firmar como ato social, enquadrando-se nas regras de economia, de consumo, de comunicação na sociedade e também como forma de diferenciação. Apesar de toda limitação imposta pela escassez de material, pela questão financeira e pelo próprio governo através das regulamentações de uso dos produtos disponíveis, a sociedade soube contornar a situação. De acordo com os autores Fiell e Dirix:

\footnotetext{
$<<$ O vestuário pode ter se tornado mais funcional, porém suas qualidades decorativas não estavam de modo algum perdidas, e, mesmo que estivesse tudo mais discreto e funcional, as roupas eram ainda intimamente ligadas à expressão de uma identidade pessoal e social (FIELL e DIRIX, 2014, p. 8).
}

A vestimenta mais funcional, sua mudança estagnada no mercado e a escassez na área têxtil permitiu a população a explorar melhor a criatividade, partindo da utilização de materiais que muitas vezes passavam despercebidos, que podiam receber uma nova função, como a decorativa. Nada de grande gastos em tecidos e aviamentos, a ordem da vez era economizar e inovar partindo de materiais que se tinha em casa, segundo Mackenzie: 
Em 1942, um manual de produção de vestuário civil foi aprovado para regulamentar critérios restritivos para a moda, limitando o uso de botões e bolsos, reduzindo costuras e bainhas e fixando até o número de pregas macho (duas) ou tombadas (quatro) para as saias. Todos os enfeites eram proibidos (MACKENZIE, 2010, p. 84).

Logo, os modelos de roupas ficaram cada vez mais simplistas devido ao pouco recurso que havia. A moda feminina agora era totalmente influenciada pela vestimenta masculina.

\section{A necessidade e a criatividade}

Embora houvesse uma grande precariedade nos materiais disponíveis durante a guerra, a população, principalmente as mulheres, usufruíram da criatividade para incrementar o visual. De acordo com Fiell e Dirix "a funcionalidade é uma qualidade raramente associada à moda, usada com maior frequência para descrever sua própria antítese: as roupas de trabalho" (FRIELL e DIRIX, 2014, p. 8). Nesse momento histórico houve a proibição do uso das meias feitas de seda, porém, devido a sua escassez e necessidade das mulheres em manter-se na moda, usufruindo da criatividade, segundo Pollini (2007), criou-se uma tintura de iodo para que as mesmas pintassem as pernas. A propaganda do produto deu-se com o seguinte slogan "Seda em suas pernas sem meia de seda". Como afirma Pollini:

\footnotetext{
$<$ Podia ser encontradas nas cores "Carne", "Carne Dourada" e "Carne Escura". Tratava-se de uma tinta com a qual as mulheres pintavam a perna para criar a ilusão de que estavam usando meias. Até a linha da costura na parte de trás das pernas, era imitada (POLLINI, 2007, p. 58).
}

O mercado preocupou-se em explorar o que mais afligia seus consumidores, e no caso do público feminino, a questão da falta da meia calça foi muito bem explorada trazendo essa opção de tinta com tonalidades diferentes para que essas mulheres pudessem adquirir um produto que solucionasse esse problema. A necessidade fez também com que mulheres usassem das sobras de tecidos para a criação de turbantes, que usaram como acessório de cabeça, pois na época deviam man- 
ter os cabelos presos por precaução nas fábricas e também, preferiam mantê-los escondidos devido à falta de tempo de arrumá-los.

\section{O efeito da guerra na moda}

Entre os anos de 1940 e 1944, mudança repentina na política e economia propiciou algumas transformações significativas na indumentária no mundo todo, da abundância de material passando rapidamente para a sua escassez. Para os autores Fiell e Dirix:

As restrições, o racionamento e as medidas de austeridade tiveram forte impacto na composição da moda. Em termos práticos, isso se traduzia em uma quantidade muito mais limitada de tecido; a seda tornou-se indisponível, pois foi direcionada aos esforços de guerra, e a lã existia em quantidades bastante reduzidas. Corantes tinham uso restrito, e dizia-se que as roupas tornaram-se monótonas, embora isso não fosse um fato universal. Tons de cinza, azul, verde e marrom dominavam a paleta (FIELL e DIRIX, 2014, p. 40).

Diante da recessão que se afligia sobre o mundo, pode-se perceber que a moda foi diretamente atingida, e na falta de algo melhor no quesito de matéria-prima, a moda precisou ser adaptada a novos ideais, além das fibras artificiais, homens e mulheres buscavam no fundo do guarda-roupa artifícios que possam ser usados na confecção de acessórios para completar os trajes. Nos Estados Unidos, criaram-se peças práticas e elegantes em grande escala, conhecido como ready-to-wear (pronto para usar) com preços mais acessíveis, as peças podiam ser compradas de casa, através de um catálogo que era entregue nas residências, nesse período que a moda para o mercado em massa foi criada e firmada até hoje.

Devido ao racionamento de petróleo no período da guerra, os carros eram usados cada vez menos, abrindo espaço para outros meios de transportes como a bicicleta, muitas mulheres precisaram adaptar-se a essa nova realidade, Blackman diz: 
quados à atividade. A Aquascutum, de Londres, produziu um conjunto de três peças com o tecido sintético "Scutum", a prova d’água e resistente ao vento. O conjunto compõe-se de casaco, saia com três pregas invertidas na frente e calça com zíperes laterais. Desse modo, a mulher pode ir de bicicleta para o trabalho, ou qualquer outro lugar, vestindo a calça para depois vestir a saia (BLACKMAN, 2011, p. 162).

Uma grande vantagem para as mulheres que precisavam trabalhar, o conjunto de três peças produzido pela Aquascutum veio num momento propício, funcional para aquelas que utilizavam da bicicleta como meio de locomoção e ao chegarem ao seu destino final não perdiam sua feminilidade.

Com o fim da guerra decretado em 1945, a população fica livre das desgraças e começando a se recompor, principalmente na Europa. Já na América, a moda ganhou espaço no cenário do pós-guerra, bem estabelecida na indústria, nesse período a moda começou a ter como sentido primordial a praticidade e a funcionalidade. A moda mostra sinais de sobrevivência à guerra exibindo looks que abusam de matéria-prima, pois, a moda da segunda metade do século apresenta-se fortemente acinturada para as mulherese para os homens, começaram a usar o linho, ternos brancos, bege, tons pastel.

\section{Considerações finais}

Através das descobertas realizadas por meio da pesquisa bibliográfica, procurou-se valorizar as superações das mulheres diante das circunstâncias e reconhecer que apesar da restrição vivida no período, contornou-se a situação usando da criatividade.

Ao longo deste período e de suas rigorosas fiscalizações, a moda conseguiu ter grandes mudanças, através da criatividade usada por todos perante uma situação atual de escassez no setor têxtil e um regime estritamente controlador.

Ressalta-se também, a importância deste período na história da moda, pois com a guerra surge uma nova maneira de fazer moda, o ready-to- wear na América e o prêt-à- porter na Europa configuram o processo de concepção e construção das roupas que conhecemos até hoje. Antes deste período todas as roupas eram feitas sob-encomenda e sob-medida para as pessoas, inexistindo o processo de produção em série. 


\section{Referências}

BLACKMAN, C. 100 anos de moda. São Paulo: Publifolha, 2011.

BRAGA, J. História da moda / João Braga. - 4. Ed. São

Paulo. Editora Anhembi Morumbi, 2004. - Coleção moda e comunicação / Kathia Castilho coordenação.

DIRIX, E; FIELL, C. A moda da década - 1940. Tradução Laura Schichvarger. - São Paulo: Publifolha, 2014.

MACKENZIE, M. Ismos: para entender a moda / Mairi Mackenzie; Tradução Christiano Sensi. - São Paulo: Editora Globo, 2010.

POLLINI, D. Breve história da moda. São Paulo:

Editora Claridade, 2007 / Coleção Saber de tudo.

SIMILI, I. Moda e gênero na Segunda Guerra Mundial: fragmentos da feminilidade "patriótica" nas aparências da primeiradama Darcy Vargas. $7^{\circ}$ Colóquio de Moda, Maringá, 2011.

STEVENSON, NJ. Cronologia da Moda: de Maria Antonieta a Alexander McQueen / NJ Stevenson; Tradução Maria Luiza X. de A. Borges. - Rio de Janeiro: Editora Zahar, 2012.

TAYLOR, K. Moda Vintage e alta-costura: um panorama de estilistas do século XX, de Paul Poiret a Alexander McQueen / Kerry Taylor; tradução Gabriela Erbetta. - São Paulo: Publifolha, 2014.

VEILLON, D. Moda \& Guerra: um retrato da França ocupada / Veillon Dominique; tradução e glossário, André Telles. - Rio de Janeiro: Jorge Zahar Ed., 2004. 